\title{
La Trinidad y un mundo entrelazado. Relacionalidad en las ciencias físicas y la teología
}

Victorino Pérez Prieto*

John Polkinghorne (Ed.). (2013). Verbo Divino, Estella, 287 pp. ISBN: 978-84-9945-970-7.

La Trinidad, el Dios trinitario, lejos de ser un tema del pasado -“una cosa de la teología de la Edad Media que nos imponían antes en el catecismo", como hemos tenido ocasión de oír más de una vez-, es un tema de actualidad, que está volviendo con fuerza en la teología cristiana y la experiencia religiosa, buscándose incluso un lugar en relación con las ciencias empíricas y las ciencias humanas contemporáneas: Dios es relación y el mundo que nos ha ido mostrando la última física, tanto el macrocosmos como el microcosmos, es pura relación; el ser humano también es relación y "la Santísima Trinidad es la mejor comunidad", como ha titulado Leonardo Boff uno de sus libros; la Trinidad, en fin, es la unidad perfecta en la diversidad. Se trata de una verdadera "reavivación y renovación de la teología trinitaria", como se reconoce en el libro sobre el que vamos a hacer una reflexión personal. Yo mismo he experimentado el interés por el Dios trinitario en la buena acogida de un libro que he publicado hace años, a pesar de ser un volumen de más de 500 páginas: Dios, Hombre, Mundo. La Trinidad en Raimon Panikkar (Pérez, 2008).

Esta reflexión trinitaria es la pretensión del libro La Trinidad y un mundo entrelazado. Relacionalidad en las ciencias físicas y la teología, en el que John Polkinghorne coordina una serie de complejos trabajos de físicos, filósofos y teólogos sobre el

* Doctor en Filosofía y Teología, autor prolífico en el campo teológico, es profesor titular de Teología Sistemática en la Facultad de Teología de la Universidad San Buenaventura. 
tema de la Trinidad en la teología ayer y hoy, la ontología relacional y la relacionalidad en la física moderna. La ontología relacional y la física quántica nos invitan, y aun obligan, a repensar la fe cristina desde sus raíces trinitarias; tras haber convertido la Trinidad en un dogma ocioso e inútil, con poca relación con la vida cristiana y redescubrir con Rahner que la Trinidad económica [el Deus ad extra o Deus pro nobis, tal como se ha manifestado en el proceso histórico de salvación] es la Trinidad inmanente [el Deus ad intra]. Algunos de los trabajos que componen el libro son de difícil lectura para un lector no especializado, y requieren especial atención, otros son más asequibles; pero todos son interesantes, formando en conjunto un libro fascinante.

Muchos lectores conocerán ya a John Polkinghorne. Para quien no es así, diremos que se trata de una figura destacada del mundo cultural británico: científico y teólogo, profesor emérito de Física Matemática en la Universidad de Cambridge y sacerdote de la Iglesia Anglicana; se ha distinguido durante décadas con numerosas publicaciones en el campo de la relación entre ciencia y religión, como presidente y fundador de la International Society for Science and Religion, premio Templeton por esos trabajos, etc. La editorial Verbo Divino ha publicado ya varios libros suyos en la colección "Teología y ciencias": La fe de un físico. Reflexiones teológicas de un pensador ascendente; La obra del amor. La creación como kénosis y el presente trabajo que estamos comentando. Polkinghorne ha publicado también en español Ciencia y teología y Explorar la realidad: la interrelación de ciencia y religión en Sal Terrae. Libros siempre interesantes y de agradable lectura para cualquiera persona interesada en este tema tan actual.

El presente trabajo me pareció fascinante cuando lo leí de una tirada al ver la luz hace ahora un año, a pesar de hacerlo en un largo viaje de avión, circunstancia que parece más propensa a lecturas más livianas que sesudas... Los títulos de los capítulos resultan expresivos; desde el que abre el libro, del mismo Polkinghorne ("El ocaso de Demócrito"), precedido por una breve pero magnífica Introducción suya, hasta el último, de la teóloga, profesora y también sacerdote anglicana Sarah Coakley ("Ontología relacional, Trinidad y ciencia"), aunque tengan una perspectiva diferente.

Polkinghorne abre el volumen con estas expresivas palabras de la introducción, que muchos compartimos con entusiasmo:

La ciencia ha encontrado cada vez más que los conceptos de atomismo y mecanismo [debe ser mecanicismo]... son incapaces para expresar plenamente el carácter de la realidad física... La historia de la física del siglo XX puede leerse como la historia del descubrimiento de muchos niveles de relacionalidad intrínseca presentes en la estructura del universo (p. 11).

Es la "conectividad holística en el mundo físico", de la que habla en el capítulo 1 aludido, y el "entrelazamiento cuántico", uno de los fenómenos más notables de la relacionalidad física, de que hablan los físicos Bub y Zeilinger en los capítulos 
2 y 3. Pero es también la relacionalidad esencial del Dios trinitario, de la que ya había hablado el mismo Tomás de Aquino: Deus est relatio; aunque se deba tener en cuenta la necesaria "flexibilidad semántica" al utilizar los conceptos. Por eso concluye Polkinghorne su introducción diciendo: "Podríamos preguntarnos qué podemos esperar razonablemente de la física en orden a iluminar cuestiones metafísicas o teológicas" (p. 15). En El ocaso de Demócrito habla de la "relacionalidad intrínseca" de toda la realidad ("la naturaleza es intrínsecamente relacional"), desde lo más elemental (partículas y campos) y luego lo biológico, hasta llegar a los humanos, "en una relacionalidad siempre creciente", y Dios mismo Padre-Hijo-Espíritu. Así, llega a concluir osadamente: "para el cristiano, la verdadera 'Teoría del Todo' es la teología trinitaria” (p. 30).

Sarah Coakley, en el capítulo-epílogo que hace el número 13, ofrece unas reflexiones sobre la relacionalidad trinitaria y el análisis filosófico de los conceptos de relación y causalidad. Distingue tres fases en el desarrollo de la doctrina trinitaria del siglo XX: La primera; en la que destaca el teólogo ortodoxo ruso Vladimir Lossky, el gran teólogo protestante suizo Karl Barth y el conocido teólogo católico jesuita alemán Karl Rahner, está centrada en oponerse al rechazo de la metafísica por parte de la Ilustración y la recuperación moderna de la Trinidad. La segunda, en la que el teólogo ortodoxo y metropolita John Zizioulas (que también colabora en este libro con un magnífico trabajo) se enfrenta al individualismo atomista, defendiendo una ontología relacional trinitaria basada en la comunión, y que ha creado una magnifica interacción entre ciencia moderna y teología. Es pena que no hable aquí la autora de la magnífica reflexión trinitaria -en línea semejante aunque con sus diferencias- de grandes teólogos como Jurgen Moltmann (1983) -apenas se alude a su libro en una pequeña nota a pie de página, y para criticarle...-, Raimon Panikkar (1999) -ni siquiera se cita una vez en este libro su original concepción trinitaria, a pesar de que su libro sobre la Trinidad tuvo numerosas ediciones en varias lenguas y la primera de ellas fue precisamente en inglés-, Leonardo Boff (1987) -cuyo libro sobre la Trinidad y la liberación es bien conocido en el área hispana-, Bárbara Andrade (1999) -teóloga germano-mexicana que publicó un magnífico volumen sobre la Trinidad en clave de ontología relacional-, o Gisbert Gresahake (2002) -que ha publicado más recientemente un voluminoso trabajo, que es de los mejores ensayos trinitarios contemporáneos: El Dios Uno y Trino. Una teología de la Trinidad-. Y una tercera fase, de reacción a esta última, por parte de algunos autores que colaboran en este libro (el ortodoxo Kallistos Ware, el católico Lewis Ayres y la misma Sarah Coakley).

Entre estos dos capítulos encontramos un conjunto de valiosos trabajos científicos, filosóficos y teológicos. Entre los primeros tenemos los capítulos del 1 al 4; además del citado de Polkinghorne, están: "El mundo entrelazado: ¿cómo puede ser eso?" de Jefrey Bub (profesor de Ciencias Físicas en la universidad de Maryland); “La física cuántica: ¿ontología o epistemología?" de Anton Zeilinger (profesor de Física en la Universidad de Viena); y “¿Un universo autosuficiente?" de Michael Heller (profesor de filosofía y miembro del Observatorio Vaticano, también Premio Templeton); a excepción de Bub, todos los autores, 
tras desarrollar su parte estrictamente física, terminan por hacer reflexiones filosóficas. Zeilinger hace afirmaciones filosóficas sobre la forma de comprender la física cuántica en la que no es posible separar ontología y epistemología, y afirma que el "entrelazamiento cuántico" pone de manifiesto que solo es posible construir una ontología de relaciones no de individuos.

Trabajos más filosóficos son los de los capítulos 5, 6 y 7: “Una introducción a la ontología relacional" de Wesley J. Wildman (profesor de Filosofía y Teología en la Universidad de Boston); “El conocimiento científico como un puente hacia la mente de Dios" de Panos A. Ligomenides (profesor de Ingeniería Informática en la Universidad de Maryland) y "Naturaleza relacional" de Argyris Nicolaidis (profesor de Física Teórica en la Universidad de Tesalónica). Wildman pone de manifiesto la enorme variedad semántica que gira en torno al concepto de relación; aunque acaba por tomar una decisión teórica que le será criticada en otros capítulos: "todas las relaciones reales son causales y por eso deberíamos desarrollar una teoría de la relación mediante una teoría amplia de la causalidad que pueda registrar las diversas calidades de relación" (p. 89). Al final de su capítulo propone, además, que comprender el mundo de modo relacional tiene consecuencias éticas importantes. El trabajo de Ligomenides desarrolla la peculiaridad de nuestro mundo relacional, repasando los hitos científicos que muestran la relacionalidad de la realidad física; y a continuación introduce lo que denomina valores evolutivos intrínsecos, que ponen de manifiesto las formas estructurales y funcionales duraderas que reflejan esta visión relacional, para concluir con unas reflexiones sobre ciencia y espiritualidad: cómo una mejor forma de hacer ciencia no puede desvincularse de una igualmente importante reflexión espiritual. El capítulo de Nicolaidis es un nuevo repaso por alguno de los hitos de la ciencia que manifiestan el carácter relacional, y utiliza el modelo triádico del filósofo pragmático Pierce para reflexionar sobre ello, aportando además la idea de que la relación fundada en el agape es el principio de relación creativa, más allá de la mera causalidad mecánica.

El resto de los capítulos son de carácter más propiamente teológicos, del 8 al 13; aquí es donde más se percibe la desigualdad de perspectivas entre los autores. Los capítulos 11 y 12, "Relación: humana y divina" de Michael Welker (profesor deTeología Sistemática en la Universidad de Heidelberg y ministro evangélico) y “Una ontología relacional reexaminada en perspectiva sociológica" de David Martin (profesor de Sociología en la London School of Economics y miembro de la Academia Británica), son intentos de ampliar la cuestión de la relacionalidad no solo a la física, sino también a la psicología (Welker) y a la sociología (Martin); el de Welker es iluminador en muchos aspectos, pone de manifiesto la complejidad inherente a una relación perceptiva con uno mismo y, como consecuencia, no se puede hablar de forma simplista de la relacionalidad entre el ser humano y Dios; pero el de Martin, quizás se pierde en demasiadas divagaciones para poner de manifiesto que las relacionalidades sociales que se pueden encontrar en las movilizaciones políticas y religiosas son, a la vez, reflejo de la relacionalidad divina y deformaciones de ese reflejo que solo será completo en un tiempo escatológico. 
Los capítulos 8, 9, 10 y el 13-epílogo, citado ya, reflejan un debate teológico entre teólogos trinitarios respecto a la interpretación de la real o supuesta brecha entre los padres Orientales (especialmente los Capadocios) y Latinos (especialmente San Agustín). El mejor de todos me parece el trabajo del Metropolita John Zizioulas "Ontología relacional: percepciones desde el pensamiento patrístico", donde expone su tesis clásica bien conocida de la precedencia de la relación sobre el ser en Dios -frente a la precedencia del ser al relacionarse como ha sido pensamiento habitual desde Aristóteles-; tal como, según él, se da en los Padres Capadocios (San Basilio, san Gregorio Nacianceno y San Gregorio de Nisa) frente a la concepción de Tertuliano y San Agustín, que priorizan la substancia frente a la relación: una substantia, tres personae. Siguiendo a los Capadocios, afirma Zizioulas: "No podemos conocer la substancia de ninguna cosa, solo nos es accesible su modo de existir. Por tanto, una ontología relacional tiene lugar al nivel del modo en que las cosas se relacionan entre sí" (p. 187). Además, "el ser no es extático, y los seres emergen de un movimiento constante de relacionalidad". Esta "confiere al ser una cualidad de amor, y, al amor, carácter ontológico: ser es existir para el otro, no para el yo" (p. 187, cursiva del autor). Como manifiesta Zizioulas, el que fue más lejos fue San Máximo el Confesor (siglo VII), que llega a afirmar que "no hay substancia 'desnuda' en el mundo... no hay substancia ninguna en el mundo que no posea su tropos, su modo de ser" (p. 188). Por eso llega a concluir Zizioulas:

La única tendencia del pensamiento patrístico que parece satisfacer los requerimientos de un diálogo entre teología y ciencias sobre la base de una ontología relacional me parece que es la representada por San Máximo... Según él, Dios y el mundo están relacionados de forma ontológica -no analógica- a través del Logos (p. 193).

Y “Una ontología relacional, si es ontología en el verdadero sentido de la palabra, no puede sino cubrir todos los aspectos, todas las áreas y todos los niveles de la existencia: el divino, el cósmico, el social" (p. 195).

Esta es la perspectiva teantropocósmica, la relacionalidad radical del ser divino (Dios "no es ni tiene substancia" porque "es pura relación") y de toda la realidad, la "relatividad radical" o "reciprocidad total", que elaboró genialmente Raimon Panikkar y he estudiado en mi libro citado (Pérez, 2008): la Realidad es teantropocósmica / trinitaria; un "tejido sin costuras" en el que están íntimamente unidos -ontológicamente relacionados- Dios, el ser humano y el cosmos. Esto supone superar el pensar dialéctico, el racionalismo dialéctico, para llegar al pensar relacional, simbólico y dialógico. Como lo indica Panikkar (2001), en su libro Íconos del misterio. La experiencia de Dios:

Dios, el Hombre y el Mundo no son uno, ni dos ni tres. No hay tres cosas ni tampoco una sola. Hay una radical relatividad, una interconexión irreductible entre la Fuente de lo que es, lo que Es y su propio Dinamismo; Padre, Hijo y Espíritu Santo; lo Divino, lo Humano y lo cósmico; la Libertad, la Conciencia y la Materia... La realidad es 
trinitaria, no dualista. Solo negando la dualidad (advaita), sin caer en la unidad, podemos aproximarnos conscientemente a ella (p.90).

Es Cristo quien nos presenta la unidad no dualista entre lo divino y lo humano, el misterio teándrico de la teología oriental; Él es el misterium coniuntionis de la Realidad divina, humana y cósmica. En fin, como expresa Panikkar (1999):

La integración de la aventura trinitaria de toda la Realidad no mengua ni la trascendencia divina ni la diferencia entre Dios y el Mundo, de manera análoga a como la unidad trinitaria no elimina la diferencia entre las personas divinas.

Pero la tesis de Zizioulas, de que en el pensamiento patrístico de Oriente se da prioridad a la relación y en el de Occidente a la substancia es objeto de críticas en los otros tres capítulos: "La santísima Trinidad: modelo del ser persona en relación" de Kallistos Ware (otro Metropolita ortodoxo y ex profesor de Oxford), un recorrido histórico por la patrística negando la interpretación de Zizioulas, y que concluye con la imagen de que el ser humano es un ícono de la Trinidad, porque la relacionalidad con los otros es constitutiva al ser humano. El artículo Aventuras (y desventuras) en la ontología trinitaria del teólogo católico Lewis Ayres (profesor de Teología en la Universidad de Durham) es más crítico, e incluso hostil, al planteamiento de Zizioulas y los "ontólogos trinitarios"; apuesta por una formulación rigurosa de los conceptos que están en juego en este debate. Pretende manifestar dos conclusiones esenciales: primera, que considera difícil "sostener el procedimiento analógico, que me parece endeble, de proyectar hacia Dios una noción de relacionalidad y suponer, después, que ésta descripción del ser divino autoriza a hacer prescripciones para la vida cristiana" (p. 181); y, segunda, que "los modos de unidad y pluralidad que los cristianos buscan son configurados no solamente por referencia a aquello que intentamos ver en la misma Trinidad, sino siempre también por la reflexión sobre el estadio del drama divino-humano en el cual nos encontramos actualmente" (p. 182). Finalmente, la teóloga anglicana Sarah Coackley, en el capítulo al que ya aludimos, "Ontología relacional, Trinidad y ciencia", al igual que Ayres, termina concluyendo que "deberíamos estar precavidos frente a expectativas de 'reflejos' directos de tal relacionalidad [la divina] en el universo físico" (p. 248).

No oculto mi posicionamiento a favor de la fascinante postura de Zizioulas, que comparte Polkinghorne y la mayor parte de los autores de este libro, que no puedo más que recomendar su lectura de nuevo. Estoy convencido de que en esta ontología relacional está lo mejor del presente y el futuro de la teología trinitaria, y es la mejor expresión del misterio de Dios como puro amor / relación / comunión.

"Todo es relación", "todo está conectado / relacionado / entrelazado", insiste también el mismo Papa Francisco en su revolucionaria encíclica Laudato si, en la que aparece 200 veces esta expresión, como una clara llamada a la superación 
de dualismos reduccionistas y llegar a una espiritualidad de comunión con todo, con Dios y con el mundo.

\section{Referencias}

Andrade, B. (1999). Dios en medio de nosotros. Esbozo de una teología trinitaria kerigmática. Salamanca: Secretariado Trinitario.

Boff, L. (1987). La Trinidad, la sociedad y la liberación. Madrid: Paulinas.

Greshake, G. (2002). El Dios Uno y Trino. Una teología de la Trinidad. Barcelona: Herder.

Moltmann, J. (1983). Trinidad y Reino de Dios. La doctrina sobre Dios. Salamanca: Sígueme.

Panikkar, R. (1999). La Trinidad. Una experiencia humana primordial (ed. aumentada). Madrid: Siruela, cuyas primeras ediciones son: (1970). The Trinity and World Religions. Icon, Person, Mystery. Bangalore: CISRS; y (1973) The Trinity and the Religious Experience of Man. Icon, Person, Mystery (ed. aumentada). London: DLT.

Panikkar, R. (2001). Íconos del misterio. La experiencia de Dios. Barcelona: Península, $3^{\text {a }}$ ed.

Pérez, V. (2008). Dios, Hombre, Mundo. La Trinidad en Raimon Panikkar. Barcelona: Herder. 